\title{
Integrating Fuzzy Delphi with Fuzzy Analytic Hierarchy Process for Multiple Criteria Inventory Classification
}

\author{
Golam Kabir ${ }^{1}$ and Razia Sultana Sumi ${ }^{2}$ \\ ${ }^{1} \mathrm{PhD}$ Student, Department of Civil Engineering, University of British Columbia, Kelowna, British Columbia, Canada. E- \\ mail: gk.raju@yahoo.com (corresponding author). \\ ${ }^{2}$ Assistant Professor, Department of Business Administration, Stamford University, Bangladesh, Dhaka, Bangladesh. E- \\ mail: sumi2681@yahoo.com
}

\author{
Production Management \\ Received March 7, 2012; revisions April 3, 2012; April 6, 2012; accepted April 12, 2012 \\ Available online June 25, 2012
}

\begin{abstract}
A systematic approach to the inventory control and classification may have a significant influence on company competitiveness. In practice, all inventories cannot be controlled with equal attention. In order to efficiently control the inventory items and to determine the suitable ordering policies for them, multiple criteria inventory classification is used. In this paper, a systematic and logical approach is structured for multiple criteria inventory classification through integrating Fuzzy Delphi Method (FDM) with Fuzzy Analytic Hierarchy Process (FAHP). Fuzzy Delphi method used to identify the most important and significant criteria and, Fuzzy AHP is used to determine the relative weights of the attributes or criteria, and to classify inventories into different categories. To accredit the proposed model, it is implemented for the 351 raw materials of switch gear section of Energypac Engineering Limited (EEL), a large power engineering company of Bangladesh. Implementation results show that the proposed method can be used in inventory classification.
\end{abstract}

Keywords: Multicriteria inventory classification, Fuzzy Delphi Method, fuzzy analytic hierarchy process, triangular fuzzy number.

\section{Introduction}

Inventory has been looked at as a major cost and source of uncertainty due to the volatility within the commodity market and demand for the value-added product. Inventory is held by manufacturing companies for a number of reasons, such as to allow for flexible production schedules and to take advantage of economies of scale when ordering stock (Nahmias, 2004). The efficient management of inventory systems is therefore a crucial element in the operation of any production or manufacturing company (Chase et al., 2006). Classification of inventory is a crucial element in the operation of any production company (Björnfot and Torjussen, 2012). Because of the huge number of inventory items in many companies, great attention is directed to inventory classification into the different classes, which consequently require the application of different management tools and policies. $\mathrm{ABC}$ inventory management deals with classification of the items in an inventory in decreasing order of annual dollar volume. The ABC classification process is an analysis of a range of items, such as finished products or customers into three categories: A- outstandingly important; B- of average importance; C- relatively unimportant as a basis for a control scheme. Each category can and sometimes should be handled in a different way, with more attention being devoted to category A, less to B, and less to C (Muller, 2003).

Sometimes, only one criterion is not a very efficient measure for decision-making. Therefore, multiple criteria decision making methods are used (Flores and Whybark, 1986,1987). Apart from other criteria like lead time of supply, part criticality, availability, stock out penalty costs, ordering cost, scarcity, durability, substitutability, reparability etc has been taken into consideration (Flores and Whybark, 1986,1987; Zhou and Fan, 2007). More studies have been done on multi-criteria inventory classification in the past 20 years. So many different methods for classifying inventory and taking into consideration multiple criteria have been used and developed (Guvenir and Erel, 1998; Partovi and Anandarajan, 2002; Lei et al., 2005; Ramanathan, 2006; Zhou and Fan, 2007; Ng, 2007; Jamshidi and Jain, 2008; Chu et al., 2008; Hadi-Vencheh, 2010; Cebi et al., 2010; $\mathrm{Yu}, 2011)$.

Flores and Whybark $(1986,1987)$ proposed the bicriteria matrix approach, wherein annual dollar usage by a joint-criteria matrix is combined with another criterion. Though this approach is interesting, it accompanies some 
limitations. Their approach becomes increasingly complicated for three or more criteria to classify inventory items and also weights of all criteria taken into account equal. Flores et al. (1992) have proposed the use of joint criteria matrix for two criteria. The resulting matrix requires the development of nine different policies and for more than two criteria it becomes impractical to use the procedure. Analytic Hierarchy Process (AHP) developed by Saaty (1980) has been successfully applied to Multicriteria inventory classification by Flores et al. (1992). The advantage of the AHP is that it can incorporate many criteria and ease of use on a massive accounting and measurement system, but its shortcoming is that a significant amount of subjectivity is involved in pairwise comparisons of criteria. They have used the AHP to reduce multiple criteria to a univariate and consistent measure. However, Flores et al. (1992) has taken average unit cost and annual dollar usage as two different criteria among others. The problem with this approach is that the annual dollar usage and the unit price of items are usually measured in different units. On the other hand, for the applicability of this approach, the unit of a criterion must not change from item to item.

Partovi and Burton (1993) applied the analytic hierarchy process (AHP) to inventory classification in order to include both quantitative and qualitative evaluation criteria. AHP has been praised for its ease of use and its inclusion of group opinions; however, the subjectivity resulting from the pair-wise comparison process of AHP poses problems. Braglia et al. (2004) integrated decision diagram with a set of analytic hierarchy process (AHP) models used to solve the various multi-attribute decision sub-problems at the different levels/nodes of the decision tree. An inventory policy matrix is defined to link the different classes of spare parts with the possible inventory management policies so as to identify the "best" control strategy for the spare stocks.

Artificial intelligence methods like neural networks, fuzzy logic (FL) and genetic algorithms (GA) are applied for multi-criteria inventory classification. An artificial intelligence concept is based on the development of the intelligent computer systems with properties similar to human intelligence. Guvenir and Erel (1998) applied genetic algorithm technique to the problem of multiple criteria inventory classification. Their proposed method is called Genetic Algorithm for Multicriteria Inventory Classification and it uses genetic algorithm to learn the weights of criteria. Partovi and Anandarajan (2002) proposed an artificial neural network (ANN) approach for inventory classification. Artificial neural network is another artificial intelligence-based technique, which is applicable to the classification process. In their approach two type of learning method, namely back propagation and generic algorithms are used to examine the ANN classification power and then their results are compared with together. Their approach finds and bringing out nonlinear relationships and interactions between criteria. However, as authors have asserted, number of criteria are restricted, also entering many qualitative criteria into model may be difficult and in addition, learning their meta-heuristics approach is difficult for inventory managers. Lei et al. (2005) compared principal component analysis with a hybrid model combining principal component analysis with artificial neural network and back propagation algorithm. Simunovic et al. (2009) investigated the application of neural networks in multiple criteria inventory classification. Various structures of a back-propagation neural network have been analyzed and the optimal one with the minimum Root Mean Square error selected. The predicted results are compared to those obtained by the multiple criteria classification using the analytical hierarchy process.

Ramanathan (2006) proposed a weighted linear optimization model for multiple criteria $A B C$ inventory classification, where performance score of each item obtained using a Data Envelopment Analysis (DEA)-like model. In the proposed approach, a weighted additive function is used to aggregate the performance of an inventory item in terms of different criteria to a single score, called the optimal inventory score of an item. The weights are chosen using optimization subject to the constraints that the weighted sum, computed using the same set of weights, for all the items must be less than or equal to one. However his model may result in a position in which an item with a high value in an unimportant criterion is inappropriately classified as class A. This drawback was rectified by Zhou and Fan (2007) via obtaining most favorable and least favorable scores for each item. $\mathrm{Ng}$ (2007) proposes a weighted linear model for MCABC inventory classification. Via a proper transformation, the $\mathrm{Ng}$ model can obtain the scores of inventory items without a linear optimizer. The Ng-model is simple and easy to understand. Despite its many advantages, Ng-model leads to a situation which the weight of an item may be ignored. To overcome this drawback Hadi-Vencheh (2010) proposed a simple nonlinear programming model which determines a common set of weights for all the items.

Liu and Huang (2006) present a modified Data Envelopment Analysis (DEA) model to address ABC inventory classification. The evaluating process has two steps. Firstly, all criteria data for each item are normalized between $[0,1]$. Then, the prior scores for all inventory items are computed using the proposed Model. Chen and $\mathrm{Qu}$ (2006) used fuzzy Quadratic Optimization Program for classifying inventory items by taking care of conflicting attributes like average unit cost, annual dollar usage, critical factor, lead time. Chu et al. (2008) have suggested a new inventory classification approach called $A B C$-fuzzy classification (ABC-FC) combining the traditional $\mathrm{ABC}$ with fuzzy classification, which can handle variables with nominal or non-nominal attribute, incorporate manager's experience, judgment into inventory classification, and can be implemented easily. Bhattacharya et al. (2007) developed a distance-based multiple-criteria consensus framework utilizing the technique for order preference by similarity to ideal solution (TOPSIS) for ABC analysis. Chen et al. (2008) proposed a case-based distance model for multiple criteria $\mathrm{ABC}$ analysis, which their approach has been arisen from Flores et al. method (Flores and Whybark, 1986,1987). Advantage of this model is that is easily considered any finite number of criteria for classification. In this model, criteria weights and sorting thresholds are generated mathematically based on the decision maker's assessment of a set the cases. But information cases are very important and if this information is incorrect affect process of classification other items, also its learning may be difficult for the average manager. 
Jamshidi and Jain (2008) addressed multi-criteria ABC inventory classification to standardized each criterion and weight them for classification. The weight for each criterion is based on simple exponential smoothing weight assignments. With inclusion of weight for each criteria and normalizing the data a score is obtained for each item and the classification is done based on the normalized score. Rezaei (2007) used fuzzy set theory and fuzzy Analytical Hierarchy Process to present a simple and applicable approach for ABC classification of inventory. Conventional AHP seems inadequate to capture decisionmaker's requirements on evaluating alternatives always contain ambiguity and multiplicity of meaning. In order to model this kind of uncertainty in human preference, fuzzy sets could be incorporated with the pairwise comparison as an extension of AHP. In this approach, at first related criteria are selected and determine the weights of these criteria using fuzzy Analytical Hierarchy Process. Then assign a score to each item for each criterion as triangular fuzzy number and calculate the final normalized weighted score of each item using fuzzy set theory. Finally, using principle for the comparison of fuzzy numbers, the final scores are compared with each other. Then all items are classified into three classes according to their final score.

Cakir and Canbolat (2008) proposed an inventory classification system based on the fuzzy analytic hierarchy process (FAHP), a commonly used tool for multi-criteria decision making problems. They integrated fuzzy concepts with real inventory data and design a decision support system assisting a sensible multi-criteria inventory classification. Cebi et al. (2010) used fuzzy analytic hierarchy process for classifying inventory items by taking care of conflicting attributes like demand, unit cost, substitutability, payment terms, and lead time. HadiVencheh and Mohamadghasemi (2011) proposed an integrated fuzzy analytic hierarchy process-data envelopment analysis (FAHP-DEA) for multiple criteria $\mathrm{ABC}$ inventory classification. FAHP-DEA methodology uses the FAHP to determine the weights of criteria, linguistic terms to assess each item under each criterion, the data envelopment analysis (DEA) method to determine the values of the linguistic terms, and the simple additive weighting (SAW) method to aggregate item scores under different criteria into an overall score for each item. Yu (2011) compared artificial-intelligence (AI)-based classification techniques with traditional multiple discriminant analysis (MDA). To test the effectiveness AIbased techniques include support vector machines (SVMs), backpropagation networks (BPNs), and the k-nearest neighbor $(\mathrm{k}-\mathrm{NN})$ algorithm, classification results based on four benchmark techniques are compared. The results show that AI-based techniques demonstrate superior accuracy to MDA. Statistical analysis reveals that SVM enables more accurate classification than other AI-based techniques. The summary of the literature on Multicriteria Inventory Classification is given in Table 1.

The previous researches used Fuzzy AHP with traditional Delphi Method for the multicriteria inventory classification. But some weaknesses have been exposed, traditional Delphi Method needs repetitive surveys to allow forecasting values to converge which requires much more time and cost (Ishikawa et al., 1993). Furthermore, in many real situations, experts' judgments cannot be properly reflected in quantitative terms. Some ambiguity will result due to the differences in the meanings and interpretations of the expert's opinions (Gupta, 2010). To remove the uncertainties and vagueness of decision making, the concept of fuzzy set theory and Delphi Method are combined to generate Fuzzy Delphi Method (FDM). Therefore the main objective of this research is to develop an improved multi-criteria inventory classification model through integrating fuzzy Delphi method with fuzzy AHP.

The remainder of this paper is organized as follows. In the next section, the proposed methodology has been described with brief note on fuzzy Delphi method and fuzzy AHP. The proposed methodology is applied to classify 351 raw materials of switch gear section of Energypac Engineering Limited (EEL), a large power engineering company of Bangladesh in the following section. Finally, the last section presents the conclusion and discusses the limitations and scope for future research.

\section{Proposed Model}

The proposed approach is aimed to explain a systematic inventory classification process integrating fuzzy Delphi method with FAHP which consists of three main phases. The detailed steps of each phase are discussed as follows:

\subsection{Fuzzy Logic to Assign Weights to the Decision Makers}

As the Decision Makers (DM) have different experience, designation and qualification, there opinion enjoys different weights in the decision making, so the weights have been assigned to the analysts on this basis. By merging the opinions of almost everybody in the senior management, it is established that the opinion of the decision maker with more experience, higher designation and bigger qualification is more reliable. The linguistic variables for the experience, designation and qualification can be quantified using triangular fuzzy numbers as per Table 2. These linguistic variables can be expressed in positive triangular fuzzy numbers, as in Fig. 1 (Gupta, 2010).

\subsection{Fuzzy Delphi Method}

Fuzzy Delphi Method (FDM) was proposed by Ishikawa et al. (1993), and it was derived from the traditional Delphi technique and fuzzy set theory. Noorderhaben (1995) indicated that applying the FDM to group decision can solve the fuzziness of common understanding of expert opinions. To shortlist the important criteria for inventory classification, fuzzy Delphi approach is used in this study. In this method, the unimportant criteria can be identified and eliminated from further consideration. The detailed steps of this preliminary screening phase are described below (Gupta, 2010): 
Table 1. Summary of multicriteria inventory classification studies

\begin{tabular}{|c|c|c|}
\hline Multiple Criteria & Method Used & Reference \\
\hline Annual dollar usage, criticality class & $\begin{array}{l}\text { Bi-criteria matrix } \\
\text { approach }\end{array}$ & Flores and Whybark, 1986 \\
\hline Average unit cost, Annual dollar usage & $\begin{array}{l}\text { Bi-criteria matrix } \\
\text { approach }\end{array}$ & Flores and Whybark, 1987 \\
\hline Obsolescence, reparability, criticality, and lead time & AHP & Flores et al., 1992 \\
\hline $\begin{array}{l}\text { Demand, unit cost, substitutability, payment terms, and lead } \\
\text { time. }\end{array}$ & AHP & Partovi and Burton, 1993 \\
\hline $\begin{array}{l}\text { University stationary inventory: Annual cost usage, No. of } \\
\text { request for item in a year, lead time, replacability }\end{array}$ & Genetic Algorithm & Guvenir and Erel, 1998 \\
\hline $\begin{array}{l}\text { Explisive inventory: Unit price, No. of request for item in a year, } \\
\text { lead time, scarcity, durability, substitutability, reparability, order } \\
\text { size requirement, stockability, commonality }\end{array}$ & & \\
\hline Unit cost, ordering cost, demand, lead time & ANN & $\begin{array}{l}\text { Partovi and Anandarajan, } \\
2002\end{array}$ \\
\hline $\begin{array}{l}\text { Inventory constraints, costs of lost production, safety and } \\
\text { environmental objectives, strategies of maintenance adopted, } \\
\text { logistics aspects of spare parts }\end{array}$ & AHP & Braglia et al., 2004 \\
\hline Average unit cost, Annual dollar usage, critical factor, lead time & $\begin{array}{l}\text { Weighted Linear } \\
\text { Optimization }\end{array}$ & Ramanathan, 2006 \\
\hline Average unit cost, annual dollar usage, critical factor, lead time & $\begin{array}{l}\text { Quadratic } \\
\text { Optimization } \\
\text { Program }\end{array}$ & Chen and Qu, 2006 \\
\hline $\begin{array}{l}\text { Unit cost, lead time, consumption rate, perishability of items and } \\
\text { cost of storing of raw materials }\end{array}$ & $\begin{array}{l}\text { Distance-based } \\
\text { multiple-criteria } \\
\text { consensus } \\
\text { framework }\end{array}$ & Bhattacharya et al., 2007 \\
\hline Annual Dollar Usage, Average Unit Cost, Lead Time & $\begin{array}{l}\text { Weighted Linear } \\
\text { Model }\end{array}$ & $\mathrm{Ng}, 2007$ \\
\hline Average unit cost, Annual dollar usage, critical factor, lead time & $\begin{array}{l}\text { Weighted Linear } \\
\text { Optimization } \\
\text { (Extended Version } \\
\text { of R model) }\end{array}$ & Zhou and Fan, 2007 \\
\hline $\begin{array}{l}\text { Unit price, annual demand, stock ability, lead time, certainty of } \\
\text { supply, }\end{array}$ & Fuzzy AHP & Rezaei, 2007 \\
\hline $\begin{array}{l}\text { Average unit cost, Annual dollar usage, Critical factor, Lead } \\
\text { time }\end{array}$ & $\begin{array}{l}\text { Dominance-based } \\
\text { rough set approach }\end{array}$ & Chen et al., 2008 \\
\hline Annual dollar usage, number of hits, average value per hit & $\begin{array}{l}\text { Exponential } \\
\text { Smoothing } \\
\text { Weights }\end{array}$ & Jamshidi and Jain, 2008 \\
\hline $\begin{array}{l}\text { Price/cost, Annual demand, Blockade effect in case of stockout, } \\
\text { Availability of the substitute material, Lead time, Common use }\end{array}$ & Fuzzy AHP & Cakir and Canbolat, 2008 \\
\hline $\begin{array}{l}\text { Annual cost usage, Criticality factor, Lead time } 1 \& 2 \text {, working } \\
\text { days }\end{array}$ & ANN & Simunovic et al., 2009 \\
\hline Annual Dollar Usage, Average Unit Cost and Lead Time & $\begin{array}{l}\text { Nonlinear } \\
\text { Programming } \\
\text { Model }\end{array}$ & Hadi-Vencheh, 2010 \\
\hline Demand, unit cost, substitutability, payment terms, and lead time & Fuzzy AHP & Cebi et al., 2010 \\
\hline Average unit cost, Annual dollar usage, critical factor, lead time & $\begin{array}{l}\text { Artificial- } \\
\text { Intelligence }\end{array}$ & Yu, 2011 \\
\hline $\begin{array}{l}\text { Annual dollar usage, Limitation of warehouse space, Average lot } \\
\text { cost, lead time }\end{array}$ & Fuzzy AHP-DEA & $\begin{array}{l}\text { Hadi-Vencheh and } \\
\text { Mohamadghasemi, } 2011\end{array}$ \\
\hline
\end{tabular}


The team of experts from industry (Decision Makers) and academics should determine all possible evaluation criteria specific to the industry prior which may vary dramatically from company to company. Each DM is asked through a questionnaire to specify the importance of the each evaluation criteria. As human judgments are often vague and cannot estimate his preference with an exact numerical number, each analyst must select the appropriate linguistic terms. Its goal is to integrate the opinions of all the DMs to eliminate the unimportant criteria. The seven linguistic terms which can be employed in the questionnaire are as follows: very low, low, medium low, medium, medium high, high, and very high as shown in Fig. 2 (Gupta, 2010).

The outcome of the questionnaire is the decision matrix as follows:

$$
\begin{aligned}
& \widetilde{X}_{1} \tilde{X}_{2} \ldots \ldots \tilde{X}_{n} \\
& \mathrm{D}_{1} \quad \mathrm{D}_{2} \ldots \mathrm{D}_{\mathrm{n}} \\
& \left.\begin{array}{c|llll}
\mathrm{C}_{1} & \widetilde{L}_{11} & \widetilde{L}_{12} & \ldots . & \widetilde{L}_{1 n} \\
\mathrm{C}_{2} & \widetilde{L}_{21} & \widetilde{L}_{22} & \ldots & \widetilde{L}_{2 n} \\
\mathrm{C}_{\mathrm{m}} & : & \vdots & : \\
\widetilde{L}_{m 1} & \widetilde{L}_{m 2} & \ldots & \widetilde{L}_{m n}
\end{array}\right]
\end{aligned}
$$

where $\mathrm{C}_{i}$ : the $i^{\text {th }}$ evaluation criterion, $i=1,2, \ldots, \mathrm{m} . \mathrm{D}_{j}$ : the $j^{\text {th }}$ analyst, $j=1,2, \ldots$, n. $X \quad j$ : weight of the $j^{\text {th }}$ analyst, $L_{i j}$ : the linguistic evaluation of criterion $i$ by the analyst $j$. Each element $L_{i j}$ in the decision matrix is represented as a triangular fuzzy number $\left(l_{i j}^{a}, l_{i j}^{b}, l_{i j}^{c}\right)$.

By using the appropriate fuzzy operators, weighted average of each criterion is calculated as follows

$$
\widetilde{W}_{i}=\frac{\sum_{j}^{n}={ }_{1} X_{J} \otimes L_{i j}}{n}
$$

where $W_{i}=$ weighted average of the $i^{\text {th }}$ criteria and $i=$ $1,2, \ldots, \mathrm{m}$. This value is defuzzified using average method by the equation given as:

$$
W_{i}=\frac{W_{a i}+W_{b i}+W_{c i}}{3}
$$

The large the number of criteria for the classification process, the more cumbersome and time consuming will be the classification process so only the important criteria are considered for the subsequent evaluation, while the unimportant criteria are eliminated. By integrating the opinions of the all the analysts, a minimum acceptable weight $R_{\delta}$ for all of the criteria are defined which is calculated as:

$$
\widetilde{R}_{\bar{o}}=\frac{\sum_{j}^{n}{ }_{1} X_{J} \otimes R_{j}}{n}
$$

Table 2. Linguistic variables and FTNs for the experience, designation and qualification

\begin{tabular}{lllll}
\hline \multicolumn{1}{c}{ Designation } & \multicolumn{1}{c}{ Qualification } & Experience & Linguistic Variables & FTN \\
\hline Up to manager & Under graduate & $0-<10$ & Low & $0.0,0.2,0.4$ \\
Manager to SM & Graduate & $10-<20$ & Average & $0.2,0.4,0.6$ \\
SM to GM & Specialized graduation & $20-<30$ & High & $0.4,0.6,0.8$ \\
Sr GM and above & Post graduate & $30-$ above & Very high & $0.6,0.8,1.0$ \\
\hline
\end{tabular}

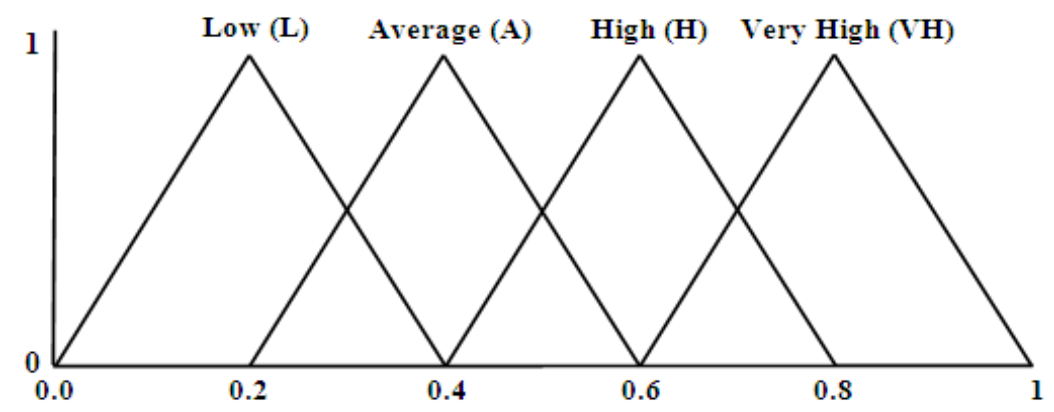

Fig. 1. Linguistic variables for experience, designation and qualification

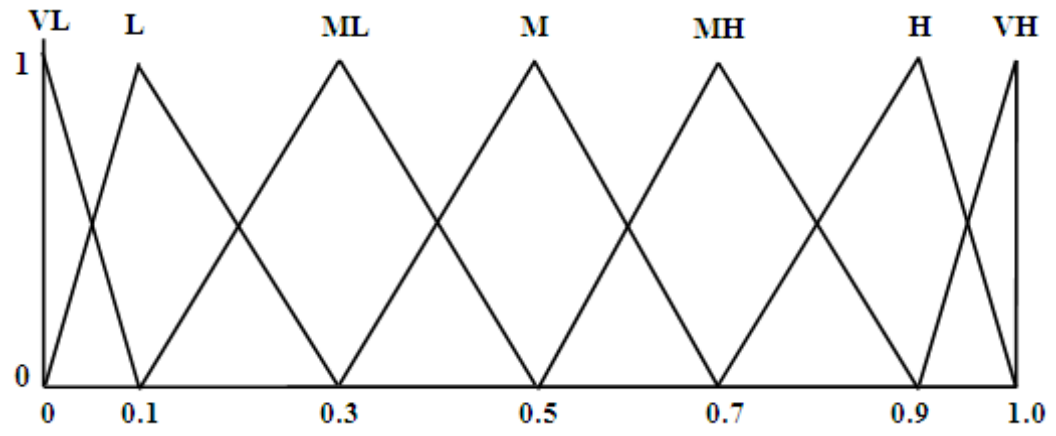

Fig. 2. Linguistic scale for relative importance 
where $R_{j}$ : the minimum acceptable weight for the criteria to be included for inventory classification defined by $j^{\text {th }}$ analyst. This value is defuzzified using average method by the equation given as:

$$
R=\frac{R_{a}+R_{b}+R_{c}}{3}
$$

A defuzzified value of ' $W_{i}$ ' is compared with the value of ' $\mathrm{R}$ '. The criterion $\mathrm{C}_{i}$ with ' $W_{i}$ ' less than the value of ' $\mathrm{R}$ ' will be eliminated. The remaining criterion will be used in the final classification phase (Gupta, 2010). This way Delphi assists the analysts to identify the important evaluation criteria and to obtain the weights of the criteria for the inventory classification.

\subsection{Fuzzy Analytic Hierarchy Process}

In the conventional AHP, the pair wise comparisons for each level with respect to the goal of the best alternative selection are conducted using a nine-point scale. So, the application of Saaty's AHP has some shortcomings as follows: (1) The AHP method is mainly used in nearly crisp decision applications, (2) The AHP method creates and deals with a very unbalanced scale of judgment, (3) The AHP method does not take into account the uncertainty associated with the mapping of one's judgment to a number, (4) Ranking of the AHP method is rather imprecise, (5) The subjective judgment, selection and preference of decision-makers have great influence on the AHP results. In addition, a decision-maker's requirements on evaluating alternatives always contain ambiguity and multiplicity of meaning. Furthermore, it is also recognized that human assessment on qualitative attributes is always subjective and thus imprecise. Therefore, conventional AHP seems inadequate to capture decision maker's requirements explicitly (Kabir and Hasin, 2011).

In order to model this kind of uncertainty in human preference, fuzzy sets could be incorporated with the pairwise comparison as an extension of AHP. A variant of AHP, called Fuzzy AHP, comes into implementation in order to overcome the compensatory approach and the inability of the AHP in handling linguistic variables. The fuzzy AHP approach allows a more accurate description of the decision making process. One of the important issues of multi-criteria decision-making is prioritization of criteria. Determining the importance of weights by managers, especially in terms of issue of MC-ABC classification, is always subjective in such a way that inventory managers usually select some important criteria and then prioritize them. There are several methods to determine of the criteria weights, including analytic hierarchy process (AHP), entropy analysis, eigenvector method, weighted least square method and linear programming for multidimensions of analysis preference (LINMAP). In this model, the method of fuzzy analytic hierarchy process (FAHP) is applied.

Generally, it is impossible to reflect the decision makers' uncertain preferences through crisp values (Rao, 2007). Therefore, FAHP is proposed to relieve the uncertainness of AHP method, where the fuzzy comparisons ratios are used. There are the several procedures to attain the priorities in FAHP. The fuzzy least square method (Xu, 2000), method based on the fuzzy modification of the least logarithmic square method (Boender et al., 1989), geometric mean method (Buckley, 1985), the direct fuzzification of the method of Csutora and Buckley (2001), synthetic extend analysis (Chang, 1996), Mikhailov's fuzzy preference programming (Mikhailov, 2003) and two-stage logarithmic programming (Wang et al., 2005) are some of these methods. Chang's extent analysis is utilized in this research to evaluate the focusing problem.

Chang (1992) introduces a new approach for handling pair-wise comparison scale based on triangular fuzzy numbers followed by use of extent analysis method for synthetic extent value of the pairwise comparison (Chang, 1996). The first step in this method is to use triangular fuzzy numbers for pairwise comparison by means of FAHP scale, and the next step is to use extent analysis method to obtain priority weights by using synthetic extent values. The fuzzy evaluation matrix of the criteria was constructed through the pairwise comparison of different attributes relevant to the overall objective using the linguistic variables and triangular fuzzy numbers (Fig. 3 and Table 3).

Table 3. Linguistic Variables Describing Weights of the Criteria and Values of Ratings

\begin{tabular}{|c|c|c|c|c|}
\hline Linguistic scale for importance & $\begin{array}{l}\text { Fuzzy } \\
\text { numbers }\end{array}$ & Membership function & Domain & $\begin{array}{l}\text { Triangular fuzzy scale } \\
\qquad(1, \mathrm{~m}, \mathrm{u})\end{array}$ \\
\hline Just equal & \multirow{2}{*}{1} & & & $(1,1,1)$ \\
\hline Equally important & & $\mu \mathrm{M}(\mathrm{x})=(3-\mathrm{x}) /(3-1)$ & $1 \leq x \leq 3$ & $(1,1,3)$ \\
\hline \multirow{2}{*}{ Weakly important } & \multirow{2}{*}{3} & $\mu \mathrm{M}(\mathrm{x})=(\mathrm{x}-1) /(3-1)$ & $1 \leq \mathrm{x} \leq 3$ & \multirow{2}{*}{$(1,3,5)$} \\
\hline & & $\mu \mathrm{M}(\mathrm{x})=(5-\mathrm{x}) /(5-3)$ & $3 \leq x \leq 5$ & \\
\hline \multirow{2}{*}{ Essential or Strongly important } & \multirow{2}{*}{5} & $\mu \mathrm{M}(\mathrm{x})=(\mathrm{x}-3) /(5-3)$ & $3 \leq x \leq 5$ & \multirow{2}{*}{$(3,5,7)$} \\
\hline & & $\mu \mathrm{M}(\mathrm{x})=(7-\mathrm{x}) /(7-5)$ & $5 \leq x \leq 7$ & \\
\hline \multirow{2}{*}{ Very strongly important } & \multirow{2}{*}{7} & $\mu \mathrm{M}(\mathrm{x})=(\mathrm{x}-5) /(7-5)$ & $5 \leq x \leq 7$ & \multirow{2}{*}{$(5,7,9)$} \\
\hline & & $\mu \mathrm{M}(\mathrm{x})=(9-\mathrm{x}) /(9-7)$ & $7 \leq x \leq 9$ & \\
\hline Extremely Preferred & 9 & $\mu \mathrm{M}(\mathrm{x})=(\mathrm{x}-7) /(9-7)$ & $7 \leq x \leq 9$ & $(7,9,9)$ \\
\hline \multirow{2}{*}{\multicolumn{3}{|c|}{$\begin{array}{l}\text { If factor } i \text { has one of the above numbers assigned to it when compared to } \\
\text { factor } j \text {, then } j \text { has the reciprocal value when compare to } i\end{array}$}} & \multicolumn{2}{|c|}{ Reciprocals of above } \\
\hline & & & M $\quad 1-1=($ & $1,1 / \mathrm{m} 1,1 / 11)$ \\
\hline
\end{tabular}

Source: Kabir and Hasin (2011) 


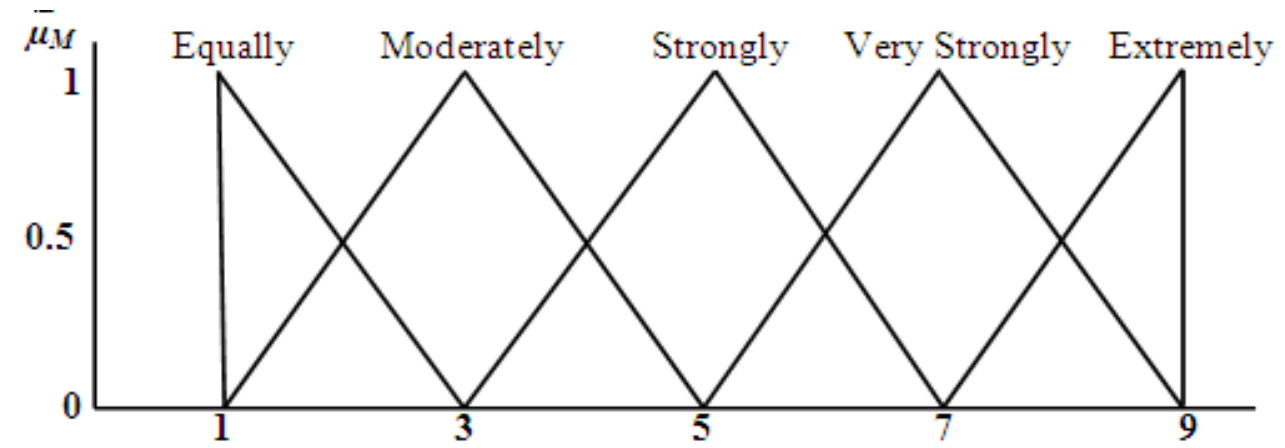

Fig. 3. Linguistic Variables for the Importance Weight of Each Criterion

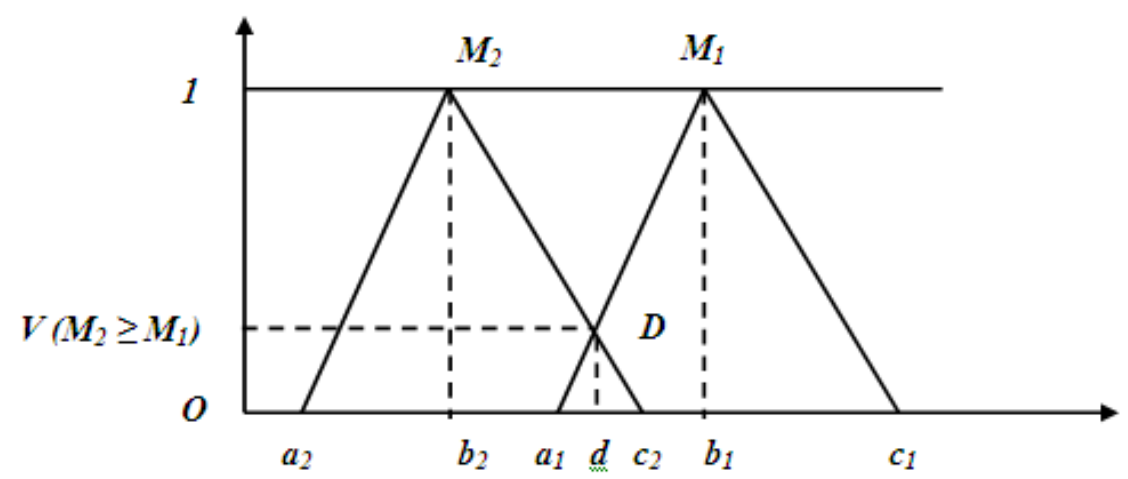

Fig. 4. The intersection between $M_{1}$ and $M_{2}$

The following section outlines the Chang's extent analysis method on FAHP. Let $\mathrm{X}=\left\{x_{1}, x_{2}, \ldots, x_{n}\right\}$ be an object set and $U=\left\{u_{1}, u_{2}, \ldots, u_{m}\right\}$ be a goal set. As per Chang $(1992,1996)$ each object is taken and analysis for each goal, $g_{i}$, is performed, respectively. Therefore $\mathrm{m}$ extent analysis values for each object can be obtained, as under:

$$
M_{g_{i}}^{1}, M_{g_{i}}^{2}, \ldots \ldots, M_{g_{i}}^{m}, i=1,2,3, \ldots \ldots, \mathrm{n}
$$

where all the $M_{g_{i}}^{m}(j=1,2, \ldots, \mathrm{m})$ are TFNs whose parameters are, depicting least, most and largest possible values respectively and represented as $(a, b, c)$.

The steps of Chang's extent analysis (Chang, 1992) can be detailed as follows (Bozbura et al., 2007; Gumus, 2009; Kabir, 2011; Kabir and Hasin, 2011):

- Step 1: The value of fuzzy synthetic extent with respect to $i$ th object is defined as

$$
S_{i}=\sum_{j=1}^{m} M_{g_{i}}^{j} \otimes\left[\sum_{i=1}^{n} \sum_{j=1}^{m} M_{g_{i}}^{j}\right]^{-1}
$$

$$
\sum_{j=1}^{m} M_{g_{i}}^{j}=\left(\sum_{j=1}^{m} a_{j}, \sum_{j=1}^{m} b_{j}, \sum_{j=1}^{m} c_{j}\right)
$$

And to obtain $\left[\sum_{i=1}^{n} \sum_{j=1}^{m} M_{g_{i}}^{j}\right]^{-1}$ perform the fuzzy addition operation of $M_{g_{i}}^{m}(j=1,2, \ldots, \mathrm{m})$ values such that

$\sum_{i=1}^{n} \sum_{j=1}^{m} M_{g_{i}}^{j}=\left(\sum_{i=1}^{n} a_{i}, \sum_{i=1}^{n} b_{i}, \sum_{i=1}^{n} c_{i}\right)$

And then compute the inverse of the vector such that

$$
\left[\sum_{i=1}^{n} \sum_{j=1}^{m} M_{g_{i}}^{j}\right]^{-1}=\left(\frac{1}{\sum_{i=1}^{n} c_{i}}, \frac{1}{\sum_{i=1}^{n} b_{i}}, \frac{1}{\sum_{i=1}^{n} a_{i}}\right)
$$

- Step 2: The degree of possibility of $M_{2}=\left(\mathrm{a}_{2}, \mathrm{~b}_{2}, \mathrm{c}_{2}\right) \geq$ $M_{1}=\left(\mathrm{a}_{1}, \mathrm{~b}_{1}, \mathrm{c}_{1}\right)$ is defined as

$$
V\left(M_{2} \geq M_{1}\right)=\sup \left[\min \left(\mu_{\mathrm{M} 1}(x), \mu_{M 2}(x)\right]\right.
$$

And can be equivalently expressed as follows:

To obtain $\sum_{j=1}^{m} M_{g_{i}}^{j}$ perform the fuzzy addition operation of $\mathrm{m}$ extent analysis values for a particular matrix such that

$$
V\left(M_{2} \geq M_{1}\right)=h g t\left(M_{1} \cap M_{2}\right)=\left\{\begin{array}{cc}
1, & \text { if } b_{2} \geq b_{1} \\
0, & \text { if } a_{1} \geq c_{2} \\
\frac{a_{1}-c_{2}}{\left(b_{2}-c_{2}\right)-\left(b_{1}-a_{1}\right)}, & \text { otherwise }
\end{array}\right.
$$

where $d$ is the ordinate of the highest intersection point $D$ between $\mu_{M_{1}}$ and $\mu_{M_{2}}$ as shown in Fig. 4 . 
To compare $M_{l}$ and $M_{2}$, both the values of $V\left(M_{1} \geq M_{2}\right)$ and $V\left(M_{2} \geq M_{1}\right)$.

- Step 3: The degree of possibility for a convex fuzzy number to be greater than $\mathrm{k}$ convex fuzzy numbers $M_{i}(i=$ $1,2, \ldots ., k)$ can be defined by

$V\left(M \geq M_{1}, M_{2}, \ldots, M_{k}\right)=V\left[\left(M \geq M_{1}\right)\right.$ and $\left(M \geq M_{2}\right)$ and $\left.\ldots\left(M \geq M_{k}\right)\right]$

$=\min V\left(M \geq M_{i}\right),(i=1,2,3, \ldots, \mathrm{k})$

Assuming that

$d^{\prime}\left(A_{i}\right)=\min V\left(S_{i} \geq S_{k}\right)$

for $k=1,2,3, \ldots, n ; k \neq i$. Then the weight vector is given by

$$
\begin{aligned}
& W^{\prime}=\left(d^{\prime}\left(A_{1}\right), d^{\prime}\left(A_{2}\right), \ldots . ., d^{\prime}\left(A_{n}\right)\right)^{T} \\
& \text { where } A i=(i=1,2,3, \ldots n) \text { are n elements }
\end{aligned}
$$

- Step 4: By normalizing, the normalized weight vectors are

$$
W=\left(d\left(A_{1}\right), d\left(A_{2}\right), \ldots \ldots, d\left(A_{n}\right)\right)^{T}
$$

where $W$ is a non-fuzzy number.

After comparison is made, it is necessary to check the consistency ratio of the comparison. To do so, the graded mean integration approach is utilized for defuzzifying the matrix. According to the graded mean integration approach, a fuzzy number $L_{x}=\left(l_{1}, l_{2}, l_{3}\right)$ can be transformed into a crisp number by employing the below equation:

$$
P(\widetilde{L})=L=\frac{l_{1}+4 l_{2}+l_{3}}{6}
$$

After the defuzzification of each value in the matrix, 'consistency ratio' (CR) of the matrix can easily be calculated and checked whether CR is smaller than 0.10 or not (Kutlu and Ekmekçioglu, 2012).

\section{Application of the Model}

To accredit the proposed model, it is implemented for the 351 raw materials of switch gear section of Energypac Engineering Limited (EEL), one of the leading power engineering companies in Bangladesh. Energypac Engineering Ltd. is the manufacturer of Transformer (Power Transformer, Distribution Transformer and Instrumental Transformer) and Switchgear (Outdoor vacuum circuit breaker, Indoor vacuum circuit breaker, Control, Metering and Relay panels, Low Tension and Power Factor Improvement panel, Indoor type Load Break Switch, Outdoor Offload disconnector and By-pass switch). Fuzzy Delphi method is used to identify the most important criteria to classify inventory. Fuzzy AHP is used to determine the relative weights of the attributes or criterions and to classify inventories into different categories through training the data set.

\subsection{Determination of Criteria}

As the DMs have different experience, designation and qualification, there opinion enjoys different weights in the decision making. Four analysts who hold the right to make the final decision (two from warehouse and store, and one from production and finance departments and further to be referred as DM 1, DM 2, DM 3 and DM 4 respectively) from the related industry are chosen to form the decision team. The weights of the decision makers are calculated based on their experience, designation and academic qualification. Decision maker 1 is production manager, specialized graduate and experience $10<20$, that means FTN are $(0.2,0.4,0.6),(0.4,0.6,0.8)$ and $(0.2,0.4,0.6)$. So the average weight of the DM $1\left(\mathrm{X}_{1}\right)$ is $(0.27,0.47,0.67)$. The weight of the other decision maker's has been determined using similar method. The weights of the decision makers are DM $1\left(\mathrm{X}_{1}\right)=(0.27,0.47,0.67)$, DM 2 $\left(\mathrm{X}_{2}\right)=(0.47,0.67,0.87)$ and to $\mathrm{DM} 3\left(\mathrm{X}_{3}\right)=$ $(0.47,0.67,0.87)$ and DM $4\left(\mathrm{X}_{4}\right)=(0.07,0.27,0.47)$ which are given in Table 1.

Based on the extensive literature review given in Table 1 , the decision team agreed to adopt the 9 criteria for inventory classification as the initial evaluation criteria used for the fuzzy Delphi process. Those are Unit price (UP), Annual demand (AD), Criticality (CR), Lead time (LT), Ordering cost (OC), Last use date (LD), Storing cost (SC), Availability (AA) and Durability (DA). Each DMs is asked through a questionnaire to specify the importance of the each evaluation criteria. Based on the decision maker's weights and judgment, the weighted aggregated value and defuzzified value of each criterion has been determined using the steps described in Fuzzy Delphi Method sub-section. Table 4 shows the judgments of the DM's and the aggregated values of the selected 9 criteria for initial evaluation.

Eliminate unimportant criteria. It was decided to select all the criteria whose weight are more than 0.40 and eliminate the rest. The selected main criteria are Unit price (UP), Annual demand (AD), Criticality (CR), Last use date (LD) and Durability (DA) (Table 4). It can be mentioned that more criteria can be selected for final classification by reducing the minimum acceptable weight $R_{\delta}$ for all of the criteria.

\subsection{Determination of the Weights of Criteria Using FAHP}

For Multicriteria inventory classification, the relative importance of each of the selected criteria is determined. The fuzzy evaluation matrix of the criteria was constructed using the linguistic variables and triangular fuzzy numbers (Fig. 3 and Table 3). The aggregation of four experts' opinions for the five criteria is performed using the following geometric mean approach. The aggregated four experts' opinions for the five criteria or attributes is computed and displayed in Table 5 using geometric mean approach (Meixner, 2009; Tang and Beynon, 2009).

$$
l_{i j}=\left(\prod_{k=1}^{K} l_{i j k}\right)^{1 / k}, m_{i j}=\left(\prod_{k=1}^{K} m_{i j k}\right)^{1 / k}, u_{i j}=\left(\prod_{k=1}^{K} u_{i j k}\right)^{1 / k}
$$

Table 5 shows the aggregated fuzzy pairwise comparisons of the four experts or decision maker's. The aggregated decision matrix as shown in Table 5 is constructed to measure the relative degree of importance for each criterion, based on the Chang's extent analysis. 
Table 4. Weighted aggregate of criteria

\begin{tabular}{|c|c|c|c|c|c|c|c|c|}
\hline \multirow{3}{*}{ Sr. No } & \multirow{3}{*}{ Criteria } & DM 1 & DM 2 & DM 3 & DM 4 & \multirow{3}{*}{$\begin{array}{l}\text { Weighted } \\
\text { Aggregated of } \\
\text { each Criteria }\end{array}$} & \multirow{3}{*}{$\begin{array}{l}\text { Defuz- } \\
\text { ified } \\
\text { Value }\end{array}$} & \multirow{3}{*}{$\begin{array}{l}\text { Select } \\
\text { or } \\
\text { Reject }\end{array}$} \\
\hline & & \multicolumn{4}{|c|}{ Weightage of the decision makers $\left(\mathrm{X}_{\mathrm{n}}\right)$} & & & \\
\hline & & $\begin{array}{c}0.47,0.67,0 . \\
87 \\
\end{array}$ & $\begin{array}{c}0.27,0.47,0 . \\
67\end{array}$ & $\begin{array}{c}0.47,0.67,0 \\
87 \\
\end{array}$ & $\begin{array}{c}0.07,0.27,0 . \\
47\end{array}$ & & & \\
\hline \multirow{2}{*}{1} & \multirow{2}{*}{ UP } & $\mathrm{H}$ & VH & $\mathrm{VH}$ & $\mathrm{H}$ & \multirow{2}{*}{$\begin{array}{c}0.261,0.496 \\
0.72\end{array}$} & \multirow{2}{*}{0.492} & \multirow{2}{*}{$\mathrm{S}$} \\
\hline & & $0.7,0.9,1$ & $0.9,1,1$ & $0.9,1,1$ & $0.7,0.9,1$ & & & \\
\hline \multirow{2}{*}{2} & \multirow{2}{*}{$\mathrm{AD}$} & $\mathrm{H}$ & VH & $\mathrm{VH}$ & $\mathrm{VH}$ & \multirow{2}{*}{$\begin{array}{c}0.264,0.503 \\
0.72\end{array}$} & \multirow{2}{*}{0.496} & \multirow{2}{*}{$\mathrm{S}$} \\
\hline & & $0.7,0.9,1$ & $0.9,1,1$ & $0.9,1,1$ & $0.9,1,1$ & & & \\
\hline \multirow{2}{*}{3} & \multirow{2}{*}{$\mathrm{CR}$} & $\mathrm{H}$ & $\mathrm{H}$ & $\mathrm{MH}$ & $\mathrm{H}$ & \multirow{2}{*}{$\begin{array}{c}0.200,0.434 \\
0.698\end{array}$} & \multirow{2}{*}{0.444} & \multirow{2}{*}{$\mathrm{S}$} \\
\hline & & $0.7,0.9,1$ & $0.7,0.9,1$ & $0.5,0.7,0.9$ & $0.7,0.9,1$ & & & \\
\hline \multirow{2}{*}{4} & \multirow{2}{*}{ LT } & $\mathrm{MH}$ & $\mathrm{MH}$ & $\mathrm{M}$ & $\mathrm{MH}$ & \multirow{2}{*}{$\begin{array}{c}0.136,0.330 \\
0.605\end{array}$} & \multirow{2}{*}{0.357} & \multirow{2}{*}{$\mathrm{R}$} \\
\hline & & $0.5,0.7,0.9$ & $0.5,0.7,0.9$ & $0.3,0.5,0.7$ & $0.5,0.7,0.9$ & & & \\
\hline \multirow{2}{*}{5} & \multirow{2}{*}{$\mathrm{OC}$} & $\mathrm{M}$ & $\mathrm{MH}$ & $\mathrm{MH}$ & $\mathrm{M}$ & \multirow{2}{*}{$\begin{array}{c}0.133,0.317 \\
0.581 \\
\end{array}$} & \multirow{2}{*}{0.344} & \multirow{2}{*}{$\mathrm{R}$} \\
\hline & & $0.3,0.5,0.7$ & $0.5,0.7,0.9$ & $0.5,0.7,0.9$ & $0.3,0.5,0.7$ & & & \\
\hline \multirow{2}{*}{6} & \multirow{2}{*}{ LD } & $\mathrm{H}$ & $\mathrm{H}$ & $\mathrm{H}$ & $\mathrm{H}$ & \multirow{2}{*}{$\begin{array}{c}0.224,0.468 \\
0.72\end{array}$} & 0470 & $\mathrm{~S}$ \\
\hline & & $0.7,0.9,1$ & $0.7,0.9,1$ & $0.7,0.9,1$ & $0.7,0.9,1$ & & $0.4 / 0$ & $\mathrm{~s}$ \\
\hline 7 & $\mathrm{SC}$ & $\mathrm{MH}$ & ML & $\mathrm{M}$ & ML & $0.102,0.256$ & 0283 & $\mathrm{P}$ \\
\hline 1 & $\mathrm{SC}$ & $0.5,0.7,0.9$ & $0.1,0.3,0.5$ & $0.3,0.5,0.7$ & $0.1,0.3,0.5$ & 0.490 & 0.283 & K \\
\hline & & $\mathrm{M}$ & $\mathrm{M}$ & $\mathrm{MH}$ & $\mathrm{H}$ & $0.126,0.320$ & & \\
\hline 8 & AA & $0.3,0.5,0.7$ & $0.3,0.5,0.7$ & $0.5,0.7,0.9$ & $0.7,0.9,1$ & 0.582 & 0.343 & $\mathrm{R}$ \\
\hline 0 & & $\mathrm{H}$ & $\mathrm{MH}$ & $\mathrm{H}$ & $\mathrm{MH}$ & $0.207,0.431$ & & $\mathrm{~S}$ \\
\hline 9 & DA & $0.7,0.9,1$ & $0.5,0.7,0.9$ & $0.7,0.9,1$ & $0.5,0.7,0.9$ & 0.691 & 0.443 & $\mathrm{~S}$ \\
\hline
\end{tabular}

Table 5. Aggregated fuzzy comparison matrix for relative importance of criteria

\begin{tabular}{cccccc}
\hline Attributes & Unit Price & Annual Demand & Criticality & Last Use Date & Durability \\
\hline Unit Price & $1,1,1$ & $0.89,1.6,2.25$ & $0.65,1.07,1.88$ & $0.82,1.47,2.76$ & $0.8,1.37,3.19$ \\
Annual Demand & $0.44,0.62,1.12$ & $1,1,1$ & $2.02,3.08,4.64$ & $0.80,1,1.47$ & $1.17,2.36,4.53$ \\
Criticality & $0.53,0.93,1.53$ & $0.22,0.34,0.50$ & $1,1,1$ & $0.68,1.11,1.66$ & $0.80,1,1.72$ \\
Last Use Date & $0.36,0.68,1.21$ & $0.68,1,1.26$ & $0.60,0.90,1.47$ & $1,1,1$ & $0.76,0.93,1.25$ \\
Durability & $0.31,0.73,1.26$ & $0.22,0.42,0.86$ & $0.58,1,1.26$ & $0.80,1.08,1.32$ & $1,1,1$ \\
\hline
\end{tabular}

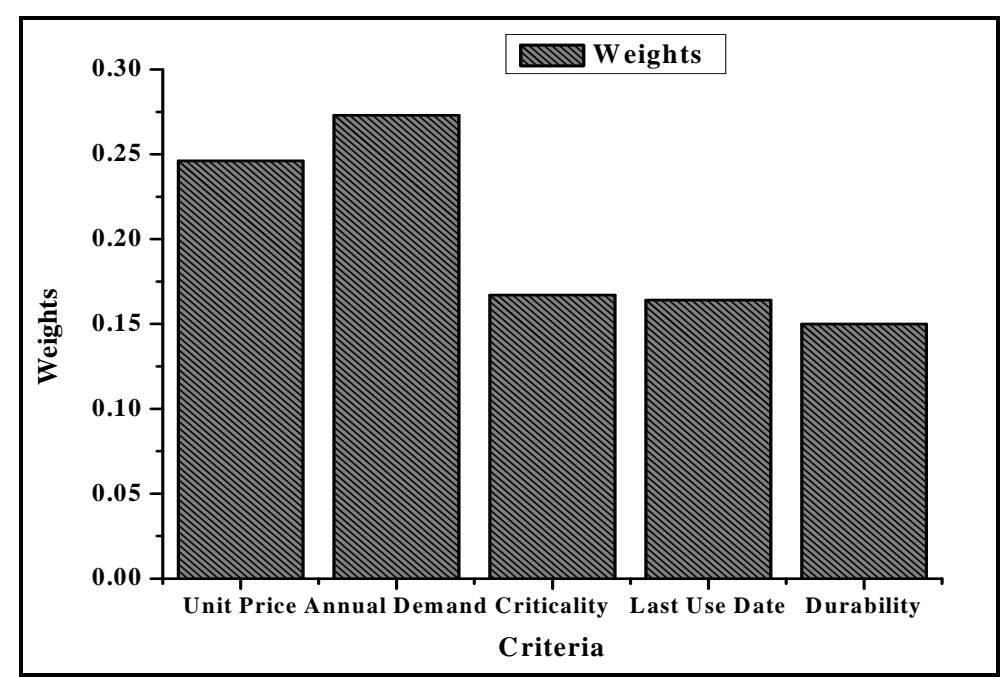

Fig. 5. Normalized weights of criteria for multiple criteria inventory classification 
Inconsistency of TFN used can be checked and the consistency ratio (CR) has to calculate. The results obtained are: largest eigen value of matrix, $\lambda_{\max }=5.323$; Consistency Index (C.I.) $=0.08075$; Randomly Generated Consistency Index (R.I.) $=1.12$ and Consistency Ratio (C.R.) $=0.0721$ As $\mathrm{CR}<0.1$ the level of inconsistency present in the information stored in comparison matrix is satisfactory (Saaty, 1998).

$S_{U}=(4.16,6.51,11.08) \otimes(1 / 42.14,1 / 27.68,1 / 19.13)$ $=(0.09,0.235,0.58)$

$S_{A}=(5.43,8.06,12.76) \otimes(1 / 42.14,1 / 27.68,1 / 19.13)$ $=(0.13,0.291,0.67)$

$$
S_{C}=(3.23,4.38,6.41) \otimes(1 / 42.14,1 / 27.68,1 / 19.13)=
$$
$(0.077,0.158,0.34)$

$S_{L}=(3.4,4.51,6.19) \otimes(1 / 42.14,1 / 27.68,1 / 19.13)=$ $(0.08,0.163,0.32)$

$S_{D}=(2.91,4.23,5.7) \otimes(1 / 42.14,1 / 27.68,1 / 19.13)=$ $(0.07,0.153,0.30)$

The degree of possibility of superiority of $S_{U}$ is calculated and is denoted by $V\left(S_{U} \geq S_{A}\right)$. Therefore, the degree of possibility of superiority for the first requirement- the values are calculated as

$$
\begin{array}{ll}
V\left(S_{U} \geq S_{A}\right)=0.9, & V\left(S_{U} \geq S_{C}\right)=1, \\
V\left(S_{U} \geq S_{L}\right)=1, & V\left(S_{U} \geq S_{D}\right)=1,
\end{array}
$$

For the second requirement- the values are calculated as

$$
\begin{array}{ll}
V\left(S_{A} \geq S_{U}\right)=1, & V\left(S_{A} \geq S_{C}\right)=1, \\
V\left(S_{A} \geq S_{L}\right)=1, & V\left(S_{A} \geq S_{D}\right)=1,
\end{array}
$$

For the third requirement- the values are calculated as

$$
\begin{array}{ll}
V\left(S_{C} \geq S_{U}\right)=0.75, & V\left(S_{C} \geq S_{A}\right)=0.61, \\
V\left(S_{C} \geq S_{L}\right)=0.98, & V\left(S_{C} \geq S_{D}\right)=1,
\end{array}
$$

For the fourth requirement- the values are calculated as

$$
\begin{array}{ll}
V\left(S_{L} \geq S_{U}\right)=0.75, & V\left(S_{L} \geq S_{A}\right)=0.60, \\
V\left(S_{L} \geq S_{C}\right)=1, & V\left(S_{L} \geq S_{D}\right)=1,
\end{array}
$$

For the fifth requirement- the values are calculated as

$$
\begin{array}{ll}
V\left(S_{D} \geq S_{U}\right)=0.70, & V\left(S_{D} \geq S_{A}\right)=0.55, \\
V\left(S_{D} \geq S_{C}\right)=0.98, & V\left(S_{D} \geq S_{L}\right)=0.96,
\end{array}
$$

The minimum degree of possibility of superiority of each criterion over another is obtained. This further decides the weight vectors of the criteria. Therefore, the weight vector is given as

$$
\mathrm{W}^{\prime}=(0.9,1,0.61,0.60,0.55)
$$

The normalized value of this vector decides the priority weights of each criterion over another. The normalized weight vectors are calculated as

$$
\mathrm{W}=(0.246,0.273,0.167,0.164,0.15)
$$

The normalized weight of each success factor is depicted in Fig. 5. Fig. 5 shows that the annual demand has higher priority than the other criteria. The weights of the criteria represent the ratio of how much more important one criterion is than another, with respect to the goal or criterion at a higher level.

\subsection{Data Collection}

Unit price, last year consumption or annual demand, last use date, criticality, durability of 351 materials of switch gear section has been collected. Among them unit price (in taka) and annual demand (number) are quantitative criteria. Range and value for the transformation of last use date, criticality and durability are shown in Table 6.

\subsection{Determination of Composite Priority Weights}

In FAHP methodology, for a very large number of alternatives (351), making pair wise comparisons of alternatives, with respect to each criterion, can be time consuming and confusing, because the total number of comparisons will also be very big. Therefore, multiple criteria inventory classification is carried out by using the modified FAHP methodology, which includes pair wise comparisons of criteria, but not pair wise comparisons of alternatives. Because of the large number of alternatives (351), pair wise comparisons of the alternatives are not performed.

Table 6. Transformation of last use date, criticality and durability

\begin{tabular}{cccccc}
\hline Last Use Date & \multicolumn{2}{c}{ Criticality } & \multicolumn{2}{c}{ Durability } \\
\hline Range & Value & Range & Value & Mean time between failure & Value \\
Used within a day & 10 & Extremely & 5 & $>1$ Week & 10 \\
Used within a week & 8 & Critical & & $>1$ Month & 8 \\
Used within a month & 6 & Moderate & 3 & $>1$ year & 5 \\
Used within 6 month & 4 & Critical & & $<1$ year & 1 \\
Used within a year & 2 & Non Critical & 1 & & 3 \\
Used more than a year & 1 & Nonth & \\
\hline
\end{tabular}


Finally, the composite priority weights of each alternative can be calculated by multiplying the weights of each alternative by the data of the corresponding criteria. The composite priority weight of the alternatives gives the idea about the appropriate class of the alternatives or items. Items are ranked according to overall composite priority weights in the descending order. There is no specific rule for the percentage selection of classes. Rezaei (2007) used fuzzy model for the classification of inventory. He classified $10 \%$ of items that have the highest normalized score as class A, $50 \%$ of the next items as class B and the rest items (about 40\%) as class C. In this research the limits for the classes are derived on the following basis. Class A involves $70 \%$ of the total composite priority weights. Class B involves $20 \%$ of the total composite priority weights amount of items, while $10 \%$ of total composite priority weights belong to class $\mathrm{C}$. The results of the study show that among 351 items 22 items are identified as class A or very important group or outstandingly important, 47 items as class B or important group or average important and the remaining 282 items as class $\mathrm{C}$ or unimportant group or relatively unimportant as a basis for a control scheme.

\section{Conclusions}

In today's manufacturing and business environment, an organization must maintain an appropriate balance between critical stock-outs and inventory holding costs. Because customer service is not a principal factor for attracting new customers, but it is frequently a major reason for losing them. Many researchers have devoted themselves to achieving this appropriate balance. Multiclass classification utilizing multiple criteria requires techniques capable of providing accurate classification and processing a large number of inventory items. In this research, a new multi-criteria inventory classification model has been proposed integrating fuzzy Delphi method with Fuzzy AHP approach.

Fuzzy linguistic terms has been employed for facilitating the comparisons between the subject criteria, since the decision makers feel much comfortable with using linguistic terms rather than providing exact crisp judgments. Fuzzy Delphi method helps to remove the uncertainties and vagueness of decision making. Here, the usage of DM's weights in fuzzy Delphi method makes the application more realistic and reliable. Fuzzy AHP technique was used to synthesize the opinions of the decision makers to identify the weight of each criterion. The FAHP approach proved to be a convenient method in tackling practical multi-criteria decision making problems. It demonstrated the advantage of being able to capture the vagueness of human thinking and to aid in solving the research problem through a structured manner and a simple process. The classification system is very flexible in the sense that the user:

a) can incorporate some other criteria or remove any criteria for his/her specific implementation;

b) can conduct different classification analyses for different inventory records;

c) can employ an application-specific linguistic variable set;

d) can substitute the crisp comparison values $\mathrm{a}_{\mathrm{ij}}$ for the fuzzy comparison values $a_{i j}$ in the optimization program, whenever the fuzzy comparisons are not available.

Further development of FAHP application could be the improvement in the determination of the weights of each component and to handle uncertainty level of the decision environment by using hybrid neuro-fuzzy models, like the quick fuzzy back propagation algorithm.

\section{References}

Bhattacharya, A., Sarkar, B., and Mukherjee, S.K. (2007). Distance-based consensus method for ABC analysis. International Journal of Production Research, 45(15), 3405-3420.

Boender, C.G.E., de Graan, J.G., and Lootsma, F.A. (1989). Multi-criteria decision analysis with fuzzy pairwise comparisons. Fuzzy Sets and Systems, 29(2), 133-143.

Björnfot, A. and Torjussen, L. (2012). Extent and Effect of Horizontal Supply Chain Collaboration among Construction SME. Journal of Engineering, Project, and Production Management, 2(1), 47-55.

Bozbura, F.T., Beskese, A., and Kahraman, C. (2007). Prioritization of human capital measurement indicators using fuzzy AHP. Expert Systems with Applications, 32(4), 1100-1112.

Braglia, M., Grassi, A., and Montanari, R. (2004). Multiattribute classification method for spare parts inventory management. Journal of Quality in Maintenance Engineering, 10 (1), 55-65.

Buckley, J.J. (1985). Fuzzy hierarchical analysis. Fuzzy Sets and Systems, 17(3), 233-247.

Cakir, O. and Canbolat, M.S. (2008). A web-based decision support system for multi-criteria inventory classification using fuzzy AHP methodology. Expert Systems with Applications, 35( 3), 1367-1378.

Cebi, F., Kahraman, C. and Bolat, B. (2010). A multiattribute ABC classification model using fuzzy AHP. Proceedings of the 40th International Conference on Computers and Industrial Engineering, Awaji, Japan, 25-28.

Chang, D.Y. (1992). Extent analysis and synthetic decision. Optimization Techniques and Applications, 1, 352-355.

Chang, D.Y. (1996). Applications of the extent analysis method on fuzzy AHP. European Journal of Operational Research, 95(3), 649-655.

Chase, R.B., Jacobs, F. R., Aquilano, N.J., and Agarwal, N.K. (2006). Operations Management for Competitive Advantage. 11th Edition, McGraw Hill, New York, USA.

Chen, Y., Li, K.W., Kilgour, D.M., and Hipel, K.W. (2008). A case-based distance model for multiple criteria $\mathrm{ABC}$ analysis. Computers \& Operations Research, 35(3), 776-796.

Chen, Y. and Qu, L. (2006). Evaluating the Selection of Logistics Centre Location Using Fuzzy MCDM Model Based on Entropy Weight. Proceedings of the 6th World Congress on Intelligent Control and Automation, Dalian, China.

Chu, C.W., Liang, G.S., and Liao, C.T. (2008). Controlling inventory by combining $\mathrm{ABC}$ analysis and fuzzy classification. Computers and Industrial Engineering, 55(4), 841-851.

Csutora, R. and Buckley, J.J. (2001). Fuzzy hierarchical analysis: The Lambda-Max Method. Fuzzy Sets and Systems, 120, 181-195. 
Flores, B.E. and Whybark, D.C. (1986). Multiple Criteria ABC Analysis. International Journal of Operations and Production Management, 6(3), 38-46.

Flores, B.E. and Whybark, D.C. (1987). Implementing Multiple Criteria ABC Analysis. Journal of Operations Management, 7(1), 79-84.

Flores, B.E., Olson, D.L., and Dorai, V.K. (1992). Management of Multicriteria Inventory Classification. Mathematical and Computer Modeling, 16(12), 71-82.

Gumus, A.T. (2009). Evaluation of hazardous waste transportation firms by using a two step fuzzy-AHP and TOPSIS methodology. Expert Systems with Applications, 36(2), 4067-4074.

Gupta, R., Sachdeva, A., and Bhardwaj, A. (2010). Selection of $3 \mathrm{pl}$ Service Provider using Integrated Fuzzy Delphi and Fuzzy TOPSIS. Proceedings of the World Congress on Engineering and Computer Science, II, San Francisco, USA.

Guvenir, H.A. and Erel, E. (1998). Multicriteria inventory classification using a genetic algorithm. European Journal of Operational Research, 105(1), 29-37.

Hadi-Vencheh, A. (2010). An improvement to multiple criteria ABC inventory classification. European Journal of Operational Research, 201(3), 962-965.

Hadi-Vencheh, A. and Mohamadghasemi, A. (2011). A fuzzy AHP-DEA approach for multiple criteria ABC inventory classification. Expert Systems with Applications, 38(4), 3346-3352.

Ishikawa, A., Amagasa, M., Shiga, T., Tomizawa, G., Tatsuta, R., and Mieno, H. (1993). The max-min Delphi method and fuzzy Delphi method via fuzzy integration. Fuzzy Sets and Systems, 55(3), 241-253.

Jamshidi, H. and Jain, A. (2008). Multi-Criteria ABC Inventory Classification: With Exponential Smoothing Weights. Journal of Global Business Issues, Winter issue.

Kabir, G. (2011). Fuzzy AHP for Contractor Evaluation in Project Management-A Case Study. International Journal of Business and Information Technology, 1(1), 85-96.

Kabir, G. and Hasin, M.A.A. (2011). Evaluation of Customer Oriented Success Factors in Mobile Commerce Using Fuzzy AHP. Journal of Industrial Engineering and Management, 4(2), 361-386.

Kutlu, A.C. and Ekmekçioglu, M. (2012). Fuzzy failure modes and effects analysis by using fuzzy TOPSISbased fuzzy AHP. Expert Systems with Applications, 39(1), 61-67.

Lei, Q.S., Chen, J., and Zhou, Q. (2005). Multiple criteria inventory classification based on principal components analysis and neural network. Proceedings of Advances in neural networks, 1058-1063, Berlin.

Liu, Q. and Huang, D. (2006). Classifying ABC Inventory with Multicriteria Using a Data Envelopment Analysis Approach. Proceedings of the Sixth International Conference on Intelligent Systems Design and Applications (ISDA'06), 1, 1185-1190, Jian, China.

Meixner, O. (2009). Fuzzy AHP Group Decision Analysis and Its Application for the Evaluation of Energy Sources 2. Proceedings of the 10th International Symposium on the Analytic Hierarchy/Network Process Multi-criteria Decision Making, Pittsburgh, Pennsylvania, USA, 1-14.
Mikhailov, L. (2003). Deriving priorities from fuzzy pairwise comparison judgements. Fuzzy Sets and Systems, 134(3), 365-385.

Muller, M. (2003). Essentials of Inventory Management. American Management Association, New York, USA.

Nahmias, S. (2004). Production and Operations Analysis. 5th Edition, Irwin/McGraw Hill, Burr Ridge, IL, USA, 213-215.

Ng, W.L. (2007). A simple classifier for multiple criteria ABC analysis. European Journal of Operational Research, 177(1), 344-353.

Noorderhaben, N. (1995). Strategic decision making. Addison-Wesley, UK.

Partovi, F. Y. and Burton, J. (1993). Using the analytic hierarchy process for $\mathrm{ABC}$ analysis. International Journal of Production and Operations Management, 13(9), 29-44.

Partovi, F.Y. and Anandarajan, M. (2002). Classifying inventory using and artificial neural network approach. Computers \& Industrial Engineering, 41(4), 389-404.

Ramanathan, R. (2006). ABC inventory classification with multiple-criteria using weighted linear optimization. Computers \& Operations Research, 33(3), 695-700.

Rao, R.V. (2007). Decision making in the manufacturing environment using graph theory and fuzzy multiple attribute decision making methods. Springer-Verlag, London.

Rezaei, J. (2007). A Fuzzy Model for Multi-Criteria Inventory Classification. Analysis of Manufacturing Systems, 167-172.

Saaty, T.L. (1980). The analytic hierarchy process. McGraw-Hill, New York, NY.

Saaty, T.L. (1998). The Analytic Hierarchy Process: Planning, Priority Setting, Resource Allocation. RWS Publications, Pittsburgh.

Simunovic, K., Simunovic, G. and Saric, T. (2009). Application of Artificial Neural Networks to Multiple Criteria Inventory Classification. Strojarstvo, 51(4), 313-321.

Tang, Y.C. and Beynon, M.J. (2009). Group decisionmaking within capital investment: a Fuzzy Analytic Hierarchy Process approach with developments. International Journal of Operational Research, 4(1), 75-96.

Wang, Y.M., Yang, J.B., and Xu, D.L. (2005). A twostage logarithmic goal programming method for generating weights from interval comparison matrices. Fuzzy Sets Systems, 152, 475-498.

$\mathrm{Xu}, \mathrm{R}$. (2000). Fuzzy least square priority method in the analytic hierarchy process. Fuzzy Sets and Systems, 112(3), 395-404.

$\mathrm{Yu}$, M.C. (2011). Multi-criteria ABC analysis using artificial-intelligence-based classification techniques. Expert Systems with Applications, 38(4), 3416-3421.

Zhou, P. and Fan, L. (2007). A note on multi-criteria $\mathrm{ABC}$ inventory classification using weighted linear optimization. European Journal of Operational Research, 182(3), 1488-1491. 


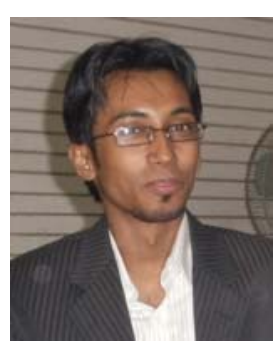

Golam Kabir is a PhD student in the Civil Engineering Department of Faculty of Applied Science at The University of British Columbia (UBC), Kelowna, British Columbia, Canada. Mr. Kabir was an Assistant Professor in the Department of Industrial and Production Engineering (IPE) at Bangladesh University of Engineering and Technology (BUET). He received a B.Sc. and a M.Sc. in Industrial and Production Engineering from BUET in 2009 and 2011 respectively. His main scientific interest concentrates on multi criteria decision analysis under risk and uncertainty, fuzzy inference system and decision support system. He has a large number of international journal publications in his credit.

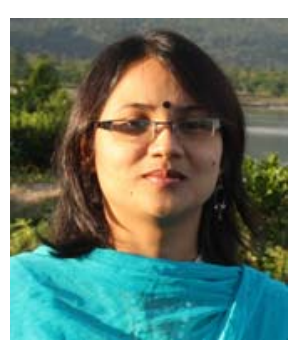

Razia Sultana Sumi is an Assistant Professor in the Department of Business Administration at Stamford University Bangladesh. She received $\mathrm{BBA}$ and $\mathrm{MBA}$ in Marketing Department from Dhaka University, Bangladesh. Her research interests are marketing and decision science. research, productivity improvement 